\title{
Accountability for an unhealthy lifestyle
}

\author{
Daniel M. Campagne ${ }^{1} \mathbb{D}$
}

Published online: 2 May 2020

c) Springer-Verlag GmbH Germany, part of Springer Nature 2020

JEL Classification I10, 11, 12, 13, 14, 15, 18, $19 \cdot \mathrm{K} 32,38$

\section{Introduction}

The right to health $[1,2]$ is fundamental: "The enjoyment of the highest attainable standard of health is one of the fundamental rights of every human being without distinction of race, religion, political belief, economic or social condition." (International Covenant on Economic, Social and Cultural Rights (ICESCR) Article 12) [3]. Human rights definitions are guidelines, to be developed in legislation.

Health care and the right to health form part of the Universal Declaration of Human Rights of 1948 (UDHR), and the World Health Organization (WHO) Alma-Ata Declaration, 1978 [4, 5]. Public "Universal" health care systems differ in coverage and financing and aim for technologies with lower incremental costs per Quality-Adjusted Life-Years (QALY) ratios (ICERs) [6]. The United Nations (U.N.) guiding principles on Business and Human Rights [7] instructs care content to depend on fair processes, not yet universally applied [8, 9].

To reduce cost, expand choice or improve care, public health coverage may combine public and private financing systems. Endemic corruption in the health industry wastes $10-25 \%$ of global health spending [10]. "Universal" health care is usually restricted to nationals, residents, taxpayers, either in general (exclusions) or specific (co-payments). Lifestyle has great relevancy, requiring improved health problem prevention through education, regulations and taxes, promoting healthier lifestyles. However, lifestyles are resistant to change. Importantly, obliging to change may infringe on human rights, impracticably waste social means,

Daniel M. Campagne

dmcampagne@gmail.com

1 Faculty of Psychology, Department of Personality, Evaluation and Psychological Treatments, Universidad Nacional de Educación a Distancia (UNED), 10 Calle Juan del Rosal, 28040 Madrid, Spain and exacerbate inequalities. The European Union, as others, pursues health equity but also admits lifestyle to be a major problem [11].

\section{Public health care is a major expenditure worldwide}

The right to health care requires public funding, thus healthy people also pay for sick people. Chronic diseases make up the greater part of health care costs and heavily depend on lifestyle. The sickest $5 \%$ of the US population consumed $50 \%$ of total health care costs whereas the healthiest $50 \%$ consumed only 3\% [12]. Even in "healthier" countries such as the Netherlands, $50 \%$ of the population has a chronic disease [13]. In Europe, chronic diseases consume $80 \%$ of overall expenditure independent of total health expenditure. Worldwide, preventable sources cause $80 \%$ of heart disease, stroke and type 2 diabetes and $40 \%$ of cancers; the US has similar figures [14, 15].

Health care expenditure grows increasingly through ageing, pollution, and changing eating habits [16]. Sociopsychological factors play a role. Care professionals are subject to high standards, requiring adequate remuneration but are influenced by politics, bureaucracy, industry and public whim. End-users have rights but few responsibilities, generating a constant upward pressure on costs.

Several human rights relate to health care, defended by the U.N. [17, 18] as "equity", including social determinants such as food, housing, life, education, privacy, access to information, and possibly gender equality. However, a counterbalancing duty for individuals to promote and protect their health remains undefined. No "fundamental human health responsibilities" have been formulated. Such accountability for health and, thus, lifestyle choices needs a legal specification, comprehending morality and the rights of others, see Article 29(2): "In the exercise of his rights and 
freedoms, everyone shall be subject only to such limitations as are determined by law solely for the purpose of securing due recognition and respect for the rights and freedoms of others and of meeting the just requirements of morality, public order and the general welfare in a democratic society." Accountability for self-inflicted health care costs is not mentioned in the U.N. Declaration on the Right and Responsibility of Individuals, Groups and Organs of Society to Promote and Protect Universally Recognized Human Rights and Fundamental Freedoms [19].

Whether an "obligation to not harm oneself" by action or omission could legitimately limit rights to health care is debated. Any obligation to self-care also infringes a person's autonomy in matters of diet, exercise, leisure activities, occupational choice, residence and family. The nature of human rights requires a legal foundation for accountability for self-harm. I define self-harm as "knowingly adopting behaviors or lifestyles with foreseeable negative consequences for health," as the narrower present clinical definition of self-harm [20] ignores that self-harm predominantly results from lifestyle.

\section{Accessibility to quality public health care depends on political choices}

Health care politics are a battlefield of legally and de facto competing institutions, partisanship and market interests. Health science evidence not necessarily converts into valid practice for public health systems. Notwithstanding increasing prevention efforts, preparedness and efficacy fail in emergencies. Self-harm through life choices occupies the greater part of capacity and aggravates conflicts. Professionals cannot oblige patients to heed advice. Heart transplant committees begin to refuse transplants to persons not willing to give up smoking. In Canada, no one is eligible for a liver transplant until having been sober for 6 months. Admission to a transplant waiting list may require lifestyle restrictions [21].

Such limited transplant access has been criticized, arguing that medical services are not based on value judgments of virtues and vices. However, self-inflicted health conditions are decisive for the care system itself. Self-harmers reduce care available for others. Two main solutions are generally considered: (a) conditioning access to treatments such as transplants and (b) recipient co-payment for certain treatments. In most countries, such conditioned access depends on individual health-center criteria, causing contradictions. The Mayo Clinic has no transplants available for a person unwilling to stop drinking alcohol or smoking [22]. At Massachusetts General Hospital, transplants are inaccessible for users of legalized marijuana. Self-harming patients with sufficient means may obtain treatments not available to non-self-harming people.

Transplant surgeons confront self-inflicted conditions [23], and ethical dilemmas affect the essence of health care $[24,25]$. Legal substances (tobacco, alcohol, food in excess) and non-substances (sedentarism) may cause rejection of the transplant.

Public health is utilitarian and aims for "the greatest good for the greatest number" [26]. No citizen can claim more than a just share. If a kidney transplant is successful in $80 \%$ of cases, but the recipient's lifestyle reduces success to a mere $40 \%$, meaning a double share.

Self-harm also thwarts other people's just health care interests. Accordingly, the South African constitutional court [27] held that providing dialysis to a patient with chronic renal failure was not required by the constitutional right to health, partly because this would prejudice the satisfaction of other health needs that have to be met out of the state's budget. Insurance plans remain out of reach of the vulnerable. Any limits on care for self-induced health conditions will disproportionately affect the poorer population.

\section{Causal accountability in public health care and third parties}

The goal of public health is to "prevent disease, promote health, and prolong life among the population as a whole" (WHO). Limited resources oblige to prioritize between competing health technologies or patient populations [28].

Personal responsibility for self-inflicted health problems is being debated publicly [29]. It is argued that the right to life includes obligations of the person the life belongs to; hence suicide or euthanasia or self-mutilation are often forbidden by law, and so should life-threatening habits. However, a person may legally eat, smoke or drug him or herself to death.

Not only is health care expenditure mainly due to selfinflicted and preventable conditions, it has considerable hidden related social costs: adequate housing, transport, social assistance, dependents and caretakers. Social effort, empathy-promoted as a duty to care for the sick, the old and the disabled, is a long-standing tradition in our societies [30]. But does a persistently self-harming citizen merit society's empathy?

Self-harm may be active, passive, sought or imposed. An example of imposed self-harm is child vaccination. An unvaccinated child is unprotected and may suffer and transmit diseases. Moral conflicts abound: is a physician legitimized to not see a patient if he or she will not change their self-harming behavior? [31]. Can parents be held responsible for imposing self-harm on their child? As mentioned, the debate not only needs to categorize 
self-harm, but also the deciding competence over lifestyle decisions.

Governments and health care authorities inform citizenry on health conditions resulting from lifestyle. Project HOPE is quantifying the considerable differences in life expectancy and disability years between healthy and unhealthy lifestyles [32]. However, lifestyle may be involuntary. Health problems resulting from the "lifestyle" of a child living in a heavily contaminated or insecure or famine area, as denounced by the International Labour Office (ILO) in the Global Estimates of Child Labour 2017 or the Maplecroft Child Labour Index 2019 [33, 34] are beyond their control.

There are many grey areas. Mental conditions reduce accountability. It can be argued that personal life choices and lifestyle are inherent results of a society model and that, by education, social instinct, or the need to fit in, a person may decide to embrace a "socially correct" but unhealthy lifestyle. Thus lifestyle choices are linked to education, income, race, gender and religion, and not necessarily free choices. Nevertheless, society needs citizens to be accountable for their actions. The consequence of an unhealthy lifestyle may be a reduction of rights to health care but only if the person did understand the hazards, had valid and accessible alternatives, and was not coerced.

A legally relevant lifestyle choice and corresponding responsibility has personal causal conditions, including behavioral characteristics, personal relationships, and personality [9]. When a person adopts a hypercaloric diet, becomes overweight and develops a severe cardiac condition, that person's accountability for the ensuing cost of a heart transplant needs to be considered. Smoking, physical inactivity, heavy alcohol intake, and obesity are risks, measured with the EuroQol five-dimensional questionnaire (EQ5D), confirming shorter life expectancy (up to 12.9 years), and substantially less Quality-Adjusted Life Expectancy (QALE) (up to 10.9 years).[35]. To determine accountability, a "responsibility grading system" could define consequences of lifestyle. However, whatever the grade of responsibility, the person's need for health care persists, and limitations will conflict with human rights as commented above.

The WHO indicates that $60 \%$ of factors determining individual health and quality of life are correlated with lifestyle. Endogenous causal factors are elusive but relevant for a to-be-established accountability. Even when persons are not accountable, perceptions of blame are quite common [9, p.1167]. The impact of accountability on health care expenditure and human rights needs further study, but initial data are challenging. Two examples of actual conflicts:

- A voluntary unhealthy lifestyle relates to dementia, irrespective of genetic risk (hazard ratio 2.83,
$N=196,383$ ) [36]. In 2015, 5-year dementia care averaged $\$ 287,038$, compared to $\$ 175,136$ for heart disease and $\$ 173,383$ for cancer. Such financial consequences for patient and family cause problems. In the US, Medicare may pay dementia care up to 100 days. Private providers have similar limits. Universal health care systems provide incomplete care, affecting poorer populations [37] that are less susceptible to change of lifestyle [38]. Accountability for self-inflicted health problems would violate human rights here.

- An involuntary unhealthy lifestyle relates to the cost of being born. A NHS analysis found that infants, born to women exposed to high levels of air pollution in the week prior to delivery, were more likely to be admitted to a newborn intensive care unit (NICU) [39]. In the US, NICU costs up to $\$ 10,000$ per day per child and comprehensive providers do not cover all expenses. NICU and related expenses could exceed \$2 million (sic) as evidenced by some published cases [40]. Involuntary unhealthy lifestyle may annul human rights.

\section{Discussion}

Public and private health care prove extremely sensitive to inadequate lifestyle choices and their medical, economic, class and gender consequences. At present, no personal accountability for their public cost has been legally formulated.

The human rights to health and health care are defined by each country signatory to U.N. and WHO Declarations. Article 29(2) UDHR states that no formal obligations may reduce access to health or health care. Nevertheless, medical or administrative guidelines regulating high-cost treatments, such as cancer therapy and transplants, do establish limitations.

Universal total and free health care proves to be a chimera. Quality health care is becoming beyond means of most economies, mainly caused by preventable diseases resulting from self-harming lifestyle. Persons knowingly damaging their health formally though not morally have the same right to care as those leading healthy lives. However, health care is a right, inherently counterbalanced by the duty not to abuse. Personal accountability for lifestyle choices may motivate change to healthier lifestyles and protect public health care capacity against unjustified depletion.

Personal accountability for the cost of treatment caused by an unhealthy lifestyle choice reflects a social responsibility for an equitable allocation of common means. However, any such legal accountability and consequences for care may exacerbate inequalities and needs other preventive and compensatory policies to achieve health equity. 
Funding There are no sources of funding.

\section{Compliance with ethical standards}

Conflict of interest The author declares that he has no conflict of interest.

\section{References}

1. World Health Organization (WHO) Basic documents, Ed. 54, 2006. https://www.who.int/governance/eb/who_constitution_ en.pdf. Accessed 15 Apr 2020

2. Daniels, N.: Just health: meeting health needs fairly, p. 2008. Cambridge University Press, Cambridge (2008)

3. International Covenant on Economic, Social and Cultural Rights (ICESCR) https://www.pwescr.org/PWESCR_Handbook_on_ ESCR.pdf. Accessed 6 Dec 2019

4. WHO Declaration of Alma-Ata. International Conference on Primary Health Care, 1978. https://www.who.int/social_determinan ts/tools/multimedia/alma_ata/en/. Accessed 12 Apr 2020

5. WHO Social Determinants of Health. https://www.who.int/gover nance/eb/who_constitution_en.pdf. Accessed 15 Dec 2019

6. Claxton, K., Paulden, M., Gravelle, H., Brouwer, W.B.F., Culyer, A.J.: Discounting and decision making in the economic evaluation of health care technologies. Health Econ. 20(1), 2-15 (2011). https://doi.org/10.1002/hec.1612

7. United Nations Guiding Principles on Business and Human Rights. https://www.ohchr.org/documents/publications/Guidingpri nciplesBusinesshr_eN.pdf. Accessed 6 Jan 2020

8. Van Exel, N.J.A., Baker, R., Mason, H., Donaldson, C., Brouwer, W.B.F., EuroVaQ Team: Public views on principles for health care priority setting: findings of a European cross-country study using Q methodology. Soc. Sci. Med. 126, 128-137 (2015). https://doi. org/10.1016/j.socscimed.2014.12.023

9. Olsen, J.A., Richardson, J., Dolan, P., Mensel, P.: The moral relevance of personal characteristics in setting health care priorities. Soc. Sci. Med. 57(7), 1163-1172 (2003). https://doi.org/10.1016/ S0277-9536(02),00492-6

10. Garcia, P. J.: Corruption in global health: the open secret. Lancet (2019). https://doi.org/10.1016/S0140-6736(19)32527-9.

11. Hanefeld, J., Reeves, A., Brown, C., Östlin, P.: Achieving health equity: democracy matters. Lancet 394, 1600-1601 (2019). https ://doi.org/10.1016/S0140-6736(19)32128-2

12. Cohen, S.: The concentration and persistence in the level of health expenditures over time: estimates for the US Population, 20122013. Statistical Brief \#481. September 2015. Agency for Healthcare Research and Quality, Rockville, MD. https://www.meps. ahrq.gov/mepsweb/data_files/publications/st481/stat481.pdf. Accessed 7 Jan 2020

13. Ministry of Public Health (Netherlands). https://www.volksgezon dheidenzorg.info/onderwerp/chronische-ziekten-en-multimorbi diteit/cijfers-context/huidige-situatie. Accessed 2 Apr 2020

14. WHO Chronic Disease Report. https://www.who.int/chp/chron ic_disease_report/part1/en/index11.html. Accessed 15 Dec 2019

15. U.S. Department of Health \& Human Services, National Center for Chronic Disease Prevention and Health Promotion (NCCDPHP), February 2019. https://www.cdc.gov/chronicdisease/about /costs/index.htm. Accessed 18 Apr 2020

16. World Bank Data, July 2019. https://data.worldbank.org/indic ator/SH.XPD.CHEX.GD.ZS. Accessed 18 Apr 2020
17. United Nations High Commissioner for Human Rights. The Right to Health, Fact Sheet No. 31, https://www.ohchr.org/ Documents/Publications/Factsheet31.pdf. Accessed 2 Apr 2020

18. United Nations Committee on Economic, Social, and Cultural Rights, General Comment 14. https://www.ohchr.org/EN/Issue s/Education/Training/Compilation/Pages/e)GeneralCommentN o14Therighttothehighestattainablestandardofhealth(article12) (2000). aspx). Accessed 2 Apr 2020

19. United Nations Declaration on the Right and Responsibility of Individuals, Groups and Organs of Society to Promote and Protect Universally Recognized Human Rights and Fundamental Freedoms (General Assembly resolution 53/144 of 9 December 1998). https://www.ohchr.org/EN/Issues/Education/Train ing/Compilation/Pages/DeclarationontheRightandResponsibil ityofIndividuals, GroupsandOrgansofSocietytoPromoteandProt ectUniversallyRecognizedHuman.aspx. Accessed 18 Dec 2019

20. Gunderson, J.G., Choi-Kain, L.W.: Working with patients who self-injure. JAMA Psych 76(9), 976-977 (2019). https://doi. org/10.1001/jamapsychiatry.2019.1241

21. NHS Blood and Transplant, 2014. Organ donation and transplantation data. www.organdonation.nhs.uk/statistics/lates t_statistics/. Accessed 6 Dec 2019

22. Mayo Clinic, Patient Care and Health Info. https://www.mayoc linic.org/tests-procedures/heart-transplant/about/pac-20384750. Accessed 2 Feb 2020

23. DiMaio, J.M., Salerno, T.A., Bernstein, R., Araujo, K., Ricci, M., Sade, R.M.: Ethical obligation of surgeons to noncompliant patients: can a surgeon refuse to operate on an intravenous drugabusing patient with recurrent aortic valve prosthesis infection? Ann. Thorac. Surg. 88(1), 1-8 (2009). https://doi.org/10.1016/j. athoracsur.2009.03.088

24. Beauchamp, T.L., Childress, J.F.: Principles of biomedical ethics, 6th edn. Oxford University Press, New York (2009)

25. Edwards, S.D.: Three versions of an ethics of care. Nurs Philos 10(4), 231-240 (2009). https://doi.org/10.1111/j.1466769X.2009.00415.x

26. Edgar, A., Salek, S., Shickle, D., Cohen, D.: The ethical qaly: ethical issues in health care resource allocation. Euromed Communications, Haslemere (1998)

27. Soobramoney V. Minister of Health, Kwazulu-Natal, 1998 (1) SA 765 (CC); 1997 (12) BCLR 1696 (CC). https://www.safli i.org/za/cases/ZACC/1997/17.html. Accessed 7 Dec 2019

28. Sabik, L.M., Lie, R.K.: Priority setting in health care: Lessons from the experiences of eight countries. Int. J. Equity Health 7, 4 (2008). https://doi.org/10.1186/1475-9276-7-4

29. Johnston, S.C.: The risk and cost of limited clinician and patient accountability in health care. JAMA (2019). https://doi. org/10.1001/jama.2019.14832

30. Prak, M.: Citizens without nations. Cambridge University Press, Cambridge (2018)

31. Mott Poll Report, August 19, 2019, 34,5. https://mottpoll. org/sites/default/files/documents/081919_VaccinePolicy.pdf. Accessed 18 Apr 2020

32. Mehta, N., Myrskylä, M.: The population health benefits of a healthy lifestyle: life expectancy increased and onset of disability delayed. Health Aff. (2017). https://doi.org/10.1377/hltha ff. 2016.1569

33. International Labour Office (ILO) (2017). Global estimates of child labour: results and trends, 2012-2016. https://www.ilo. org/wcmsp5/groups/public/---dgreports/---dcomm/documents/ publication/wcms_575499.pdf. Accessed 7 Apr 2020

34. Maplecroft. Child Labour Index, 2019. https://www.maplecroft .com/risk-indices/child-labour-index/. Accessed 7 Apr 2020 
35. Jia, H., Zack, M.M., Gottesman, I.I., Thompson, W.W.: Associations of smoking, physical inactivity, heavy drinking, and obesity with quality-adjusted life expectancy among US adults with depression. Value Health 21(3), 364-371 (2018). https://doi. org/10.1016/j.jval.2017.08.002

36. Lourida, I., Hannon, E., Littlejohns, T.J., et al.: Association of lifestyle and genetic risk with incidence of dementia. JAMA (2019). https://doi.org/10.1001/jama.2019.9879

37. Castro, M.C., Massuda, A., Almeida, G., et al.: Brazil's unified health system: the first 30 years and prospects for the future. Lancet 2019(394), 345-356 (2020). https://doi.org/10.1016/S0140 -6736(19)31243-7

38. Feng, X., Girosi, F., McRae, I.S.: People with multiple unhealthy lifestyles are less likely to consult primary healthcare. BMC Fam. Pract. 15, 126 (2014). https://doi.org/10.1186/1471-2296-15-126
39. Seeni, I., Williams, A., Nobles, C., Chen, Z., Sherman, S., Mendola, P.: Acute air pollution exposure and NICU admission: a case-crossover analysis. Ann. Epidemiol. (2019). https://doi. org/10.1016/j.annepidem.2019.07.008

40. The Guardian Jan 16, 2018. Bankrupted by giving birth. https ://www.theguardian.com/us-news/commentisfree/2018/jan/16/ bankrupted-by-giving-birth-having-premature-twins-cost-meeverything. Accessed 18 April 2020

Publisher's Note Springer Nature remains neutral with regard to jurisdictional claims in published maps and institutional affiliations. 